\title{
Couples' Opinion and Women's Utilization of Postnatal Care Service in Wolaita Zone, Southern Ethiopia: A Community Based Mixed Study
}

\author{
Wolde Facha*, Mihretu Alemayehu, Mengistu Meskele, Teshale Fikadu \\ School of Public Health, College of Health Sciences and Medicine, Wolaita Sodo University, Wolaita Sodo, Ethiopia \\ Email address: \\ woldiefacha@gmail.com (W.Facha),mihiretua@gmail.com (M. Alemayehu),mengistu77@gmail.com (M. Meskele), \\ fikaduteshale1@gmail.com (T. Fikadu) \\ ${ }^{*}$ Corresponding author
}

\section{To cite this article:}

Wolde Facha, Mihretu Alemayehu, Mengistu Meskele, Teshale Fikadu. Couples' Opinion and Women's Utilization of Postnatal Care Service in Wolaita Zone, Southern Ethiopia: A Community Based Mixed Study. Science Journal of Public Health. Vol. 5, No. 4, 2017 , pp. $288-293$. doi: $10.11648 /$ j.sjph.20170504.12

Received: April 6, 2017; Accepted: April 24, 2017; Published: May 20, 2017

\begin{abstract}
Postnatal period is the most neglected period though it is a critical phase in the lives of mothers and newborn babies. About 50 to 71 percent of maternal deaths occur during this period, particularly in the first few hours. Therefore, this study aimed to assess couples' opinion \& women's utilization of postnatal care service in Wolaita zone, Southern Ethiopia, January 2016. A community based cross sectional study was employed using both quantitative and qualitative methods of data collection. Study subjects were women aged between 15-49 years old who delivered within the past one year before data collection time in the selected districts of Wolaita zone. Multistage sampling technique was used to select study subjects for quantitative study and purposive sampling was used to select participants for qualitative study. A total of 790 sample size for quantitative data was allocated proportionally to the population size of randomly selected kebele and 24 in-depth interviews with key informants was conducted to supplement quantitative study. Bivariate and multivariate analysis was performed to assess independent predictors of postnatal care service utilization. In-depth interview was audio recorded, transcribed, translated and triangulated with quantitative findings. The prevalence of postnatal care service utilization in this study was $34.9 \%$. This study showed that younger mothers, $[\mathrm{AOR}=1.82,(95 \% \mathrm{CI}=1.23,2.69)]$; those mothers who followed antenatal care service in their last pregnancy, $[\mathrm{AOR}=10.39,(95 \% \mathrm{CI}=4.99,21.60)]$; who delivered their last child in health facilities, $[\mathrm{AOR}=2.66,(95 \% \mathrm{CI}=1.75,4.03)]$; who have good knowledge on postnatal care service utilization, $[\mathrm{AOR}=7.25,(95 \% \mathrm{CI}$ $=4.30,12.21)]$; and whose couples' have good attitude towards postnatal care service utilization, $[\mathrm{AOR}=1.76,(95 \% \mathrm{CI}=$ $1.16,2.69)]$ were more likely utilized postnatal care service than their counter parts. Postnatal care service utilization was low in the study area. Maternal age, maternal health service utilization (antenatal care service and institutional delivery), maternal knowledge and couples' attitude were major predictors for postnatal care service utilization in the study area. Concerned body should focus on the above issue to improve maternal and child health.
\end{abstract}

Keywords: Couples' Opinion, Postnatal Care Service, Wolaita Zone, Southern Ethiopia

\section{Introduction}

The World Health Organization (WHO) stated that postnatal period begins immediately after birth of the baby and extends up to six weeks (42 days) after birth [1]. It is a primary health care given to mother and newborn by health professionals (physicians, health officers, midwives, and nurses) in health facilities and at home [2-3]. Most maternal deaths (50 to $70 \%$ ) occur during this period, particularly in the first few hours (a critical phase in the lives of mothers and newborn babies) [4]. Appropriate postnatal care (PNC) in the first hour and days following childbirth prevents the great majority of maternal and child morbidity and mortality $[1,5]$. It is important for mothers not only to treat complications related to childbirth such as hemorrhage and infection, but also an opportunity for mothers and newborns to establish 
and maintain maternal and child health service [6-13]. However, an analysis of Demographic and Health Survey data from 23 Sub-Saharan African countries found that only $13 \%$ of women who delivered at home received postnatal care service within 2 days of birth [14]. It showed that majority of mothers did not utilize postnatal care service due to different factors. This was not different in Ethiopia and thus a great majority of mothers still had not been benefited from the service [15-16]. Thus, understanding the factors related PNC utilization is critical for countries like Ethiopia with alarmingly high maternal mortality. Even though postnatal care service utilization plays a critical role in reducing maternal and newborn child mortality, little is known about its determinants particularly in the study area. This study, therefore, aimed to identify couples' opinion and factors affecting PNC service utilization among child bearing age women who gave birth in the past one year preceding this survey in Wolaita zone, Southern Ethiopia.

\section{Methods and Materials}

\subsection{Study Area and Setting}

The study was conducted in three randomly selected districts of Wolaita zone [one of 13 zones in Southern Nations Nationalities and Peoples' Region (SNNPR)]. The zone is administratively divided in to 12 districts and 3 city administrations with total population of $1,838,073$ (51\% female $\& 49 \%$ male) for the year 2014/15 which was projected from 2007 Central Statistical Agency. Wolaita zone is characterized by high rural population in which $88.3 \%$ of population live in rural and $95 \%$ of population belongs to Wolaita ethnic group.

\subsection{Study Design and Period}

A community based cross sectional study design was employed by using both quantitative (structured survey questionnaire) and qualitative (in-depth interview) methods of data collection in January 2016.

\subsection{Sample Size Determination and Sampling Techniques}

The sample size for quantitative study was calculated by using single population proportion formula by assuming proportion of postnatal care service utilization 37.2\% [16], 5\% margin of error and $95 \%$ confidence interval. Finally, by taking $10 \%$ non-response rate and using design effect of 2 , the minimum sample size was 790. A multistage sampling technique was used to select the study subjects. One city administration and three rural districts were selected by simple random sampling technique from three city administrations and twelve rural districts respectively. Eight kebele (the smallest administrative unit in the country) were selected (two kebele from each stratum) and total sample size was allocated proportionally to the population size of randomly selected kebele. List of households in which eligible mothers resided were identified from respective health posts (the least government health facility structure serving for about five thousand people at kebele level) and were selected by systematic random sampling technique. If there were more than one mother within the same household, lottery method was used to select the mother. For qualitative study purposive sampling was used to select participants for in-depth interview.

\subsection{Operational Definitions}

a) Postnatal care - is a care given to a mother (age between 15-49 years) and her newborn by skilled health professionals (physicians, health officers, midwives, and nurses) any time during the first six weeks after delivery in health facilities or at their home.

b) Postpartum period- is the time from delivery of infant through the first six weeks (42days) of an infant's life.

c) Utilization of postnatal care - a mother and her newborn baby obtaining postnatal care service by skilled health professionals (physicians, health officers, midwives, or nurses) at least once during the first six weeks after delivery in health facilities or at their home.

d) Knowledge on PNC utilization - a mother is said to have good knowledge if she responded to all of four knowledge questions (timing, frequency, danger signs, benefits) related to postnatal care service. However, if she missed one of the questions she was categorized as poor knowledge on postnatal care utilization.

e) Good attitude towards PNC utilization - couples' who scored above mean to seven of attitude related questions to postnatal care (understood benefits of PNC, provide care during postnatal period, provide support (financial, moral, emotional), accompany wife during PNC and remind date of postnatal visit) were categorized as having good attitude.

f) Poor attitude towards PNC utilization - couples' who scored below mean to seven of attitude related questions to postnatal care service were categorized as having poor attitude.

\subsection{Tools and Measurement}

For quantitative study pre-tested, interviewer administered structured questionnaire which addressed socio-demographic characteristics, obstetric history, knowledge on postnatal care service, utilization of PNC service, service related to postnatal care and couples' attitude toward postnatal care service were used. Maternal knowledge on postnatal care service was addressed by four questions (timing, frequency, danger signs and benefits) related to postnatal care service. A mother is said to have good knowledge if she responded to all of four knowledge questions related to postnatal care service and those who didn't know even one of four questions were categorized as having poor knowledge. Attitude towards postnatal care service were addressed by seven questions (understood benefits of PNC, provide care during postnatal period, provide support (financial, moral, emotional), accompany wife during PNC and remind date of postnatal visit). Those couples who scored above mean to seven of attitude related questions were categorized as having good attitude and those who scored 
below mean were categorized as having poor attitude towards postnatal care service utilization. For qualitative study in-depth interview were conducted with purposively selected key informants. It focused mainly on knowledge on PNC utilization, attitude towards PNC utilization, barriers on utilization of postnatal care service and factors associated to utilization of postnatal care service.

\subsection{Data Collection}

Data collectors with the help of guider from community leaders addressed selected mothers and collected quantitative data via face to face interview method until the expected sample size was obtained. Seven midwives and four supervisors who have first degree on public health were participated during data collection process. For qualitative study one health extension worker from each kebele, delivery case team coordinators of the catchment health center, 21 husbands whose wives were delivered within the past one year prior to data collection were participated to assess couples' opinion and factors associated with postnatal care service utilization by using semi structured in-depth interview guide. A digital recorder was used during interview to record every discussion points.

\subsection{Data Quality Assurance}

The English version questionnaire was translated to Wolaitigna (the local language) and back translated to English by another person who was blinded for English version. Two days training was given for both data collectors and supervisors by the principal investigator. Questionnaire was pre-tested on $5 \%$ of women in the nearby district to identify the clarity of question, sequence of question and gap on data collector. Discussion was held based on the result of the pre-test to make necessary correction. Data were checked for completeness by supervisors on daily base and double entry was done by principal investigator before analysis.

\subsection{Data Analysis}

Data was edited, coded and entered into Epi data version 3.1 and transported to SPSS 20 statistical software for analysis. After cleaning data for inconsistencies and missing value in SPSS, descriptive statistics such as frequency and percentage were computed. Bivariate analysis was done and all explanatory variables which have association with the outcome variable at $p$ value of less than 0.2 were selected for multivariate analysis. Then multivariate analysis using forward LR method was done to determine presence of statistically significant association between explanatory variables and the outcome variable (postnatal care service utilization). P value less than 0.05 and $\mathrm{OR}$ with $95 \% \mathrm{CI}$ was used to measure presence and degree of association between independent and outcome variables respectively. Finally qualitative data was transcribed, translated and triangulated with quantitative findings.

\subsection{Ethical Consideration}

Ethical approval and clearance was obtained from Wolaita Sodo University Ethical Review Committee and letter of cooperation was obtained from Wolaita zonal health department to selected district health office and then to the respective kebele from district health office. Verbal informed consent was obtained from the study participants by informing the purpose of the study.

\section{Results}

\subsection{Socio-demographic Characteristics}

A total of 756 study participants were included in this study making a response rate of $95.7 \%$. Majority, 425(56.2\%) of them were protestant by religion, 690(91.3\%) has age below 35 years, 742(98.1\%) were married and 524(69.3\%) were house wife. However, 497(65.7\%) of their husbands attended formal education and 471(62.3\%) were farmers (Table 1).

Table 1. Socio-demographic characteristics of mothers/care givers in Wolaita zone, Southern Ethiopia, January 2016.

\begin{tabular}{lll}
\hline Variable & Number (\%) & P value \\
\hline $\begin{array}{l}\text { Religion } \\
\text { Orthodox }\end{array}$ & $286(37.8 \%)$ & 0.245 \\
$\begin{array}{l}\text { Protestant } \\
\text { Catholic }\end{array}$ & $425(56.2 \%)$ & \\
Age of mother & $45(6.0 \%)$ & 0.001 \\
$15-24$ & $202(26.7 \%)$ & \\
$25-34$ & $488(64.6 \%)$ & \\
$35-64$ & $66(8.7 \%)$ & 0.122 \\
$\begin{array}{l}\text { Marital status of mothers } \\
\text { Married }\end{array}$ & $742(98.1 \%)$ & \\
$\begin{array}{l}\text { Divorced/Widowed } \\
\text { Maternal education }\end{array}$ & $14(1.9 \%)$ & 0.009 \\
$\begin{array}{l}\text { Formal education } \\
\text { No formal education }\end{array}$ & $462(61.1 \%)$ & \\
$\begin{array}{l}\text { Maternal occupation } \\
\text { House wife }\end{array}$ & $294(38.9 \%)$ & 0.013 \\
$\begin{array}{l}\text { Others } \\
\text { Paternal education }\end{array}$ & $524(69.3 \%)$ & \\
$\begin{array}{l}\text { Formal education } \\
\text { No formal education }\end{array}$ & $232(30.7 \%)$ & 0.129 \\
$\begin{array}{l}\text { Fathers occupation } \\
\text { Farmer }\end{array}$ & $497(65.7 \%)$ & \\
Others & $259(34.3 \%)$ & 0.001 \\
\hline
\end{tabular}

\subsection{Mothers and Their Children Related Conditions}

About $477(63.1 \%)$ of mother's age during their first pregnancy was between 18 to 34 years and most of them, $576(76.2 \%)$ were not empowered at their home. About $323(42.7 \%)$ of last children's age was below 6 months and $51(6.7 \%)$ of the children were ever initiated complementary feeding before the recommended 6 months(Table 2).

Table 2. Mothers and their children related conditions in Wolaita zone, Southern Ethiopia, January 2016.

\begin{tabular}{lll}
\hline Variables & Number (\%) & P value \\
\hline Age at first pregnancy & & 0.007 \\
$<18$ & $279(36.9 \%)$ & \\
$18-34$ & $477(63.1 \%)$ & \\
\hline
\end{tabular}




\begin{tabular}{lll}
\hline Variables & Number (\%) & P value \\
\hline Maternal empowerment & & 0.03 \\
Not empowered & $576(76.2 \%)$ & \\
Empowered & $180(23.8 \%)$ & \\
Total number of children per house & & 0.001 \\
$<5$ & $581(76.9 \%)$ & \\
$>5$ & $175(23.1 \%)$ & \\
Age of last child & & 0.23 \\
42 days - 6 months & $323(42.7 \%)$ & \\
$6-12$ months & $433(57.3 \%)$ & \\
Ever initiated complementary feeding & & \\
before 6 months & & 0.261 \\
Yes & $51(6.7 \%)$ & \\
No & $705(93.3 \%)$ & \\
\hline
\end{tabular}

\subsection{Maternal and Child Health Service Utilization}

Overall prevalence of postnatal care service utilization in this study was 264(34.9\%) and about 554(73.3\%) of mothers got antenatal care service in their last pregnancy. However, more than half, $498(65.9 \%)$ and $481(63.6 \%)$ of the mothers did not utilize institutional delivery and modern family planning service. Concerning child health service, $601(79.5 \%)$ of their children were vaccinated for their age. About $718(95 \%)$ of mothers resided within one hour distance to get health service from health post. Only $141(18.7 \%)$ of mothers have good knowledge on postnatal care service utilization and $268(35.4 \%)$ of their couples' have good attitude towards postnatal care service utilization (Table 3).

Table 3. Maternal and child health service utilization related factors in Wolaita zone, Southern Ethiopia, January 2016.

\begin{tabular}{lcl}
\hline Variables & Number (\%) & P value \\
\hline Got ANC in last pregnancy & & 0.001 \\
Yes & $554(73.3 \%)$ & \\
No & $202(26.7 \%)$ & \\
\hline
\end{tabular}

\begin{tabular}{lll}
\hline Variables & Number (\%) & P value \\
\hline $\begin{array}{l}\text { Place of delivery } \\
\text { Home }\end{array}$ & 0.001 \\
$\begin{array}{l}\text { Health facility } \\
\text { Child vaccinated for their age }\end{array}$ & $498(65.9 \%)$ & \\
Yes & $258(34.1 \%)$ & \\
No & $718(95.0 \%)$ & \\
$\begin{array}{l}\text { Distance to Health Post } \\
<60 \text { min }\end{array}$ & $38(5.0 \%)$ & \\
$>60$ min & $718(95.0 \%)$ & \\
$\begin{array}{l}\text { Distance to Health Center } \\
<60 \text { min }\end{array}$ & $38(5.0 \%)$ & \\
$>$ >60min & $270(35.7 \%)$ & \\
$\begin{array}{l}\text { Maternal knowledge on PNC utilization } \\
\text { Poor knowledge }\end{array}$ & $486(64.3 \%)$ & \\
$\begin{array}{l}\text { Good knowledge } \\
\text { Couples' attitude towards PNC service } \\
\text { utilization }\end{array}$ & $615(81.3 \%)$ & \\
$\begin{array}{l}\text { Poor attitude } \\
\text { Good attitude }\end{array}$ & $141(18.7 \%)$ & \\
\hline
\end{tabular}

\subsection{Multivariate Analysis}

Marital status, mothers' age, maternal occupation, maternal education, fathers' occupation, fathers' education, women's empowerment, mothers' age at first pregnancy, antenatal care service utilization at last pregnancy, place of delivery, maternal knowledge on postnatal care service, couples' attitude towards postnatal care service utilization were candidate variables in bivariate analysis with $\mathrm{p}$ value less than 0.2 . After controlling for confounders, five variables such as mothers' age at first pregnancy, ANC service utilization at last pregnancy, place of delivery, maternal knowledge on postnatal care service, and couples' attitude towards postnatal care service utilization has shown statistically significant association in the final model (Table 4).

Table 4. Multivariate analysis of postnatal care service utilization among women who gave birth in the past 12 months prior to data collection in Wolaita zone, Southern Ethiopia, January 2016.

\begin{tabular}{|c|c|c|c|}
\hline Variables & Number (\%) & $\operatorname{COR}(95 \% \mathrm{CI})$ & $\operatorname{AOR}(95 \% \mathrm{CI})$ \\
\hline \multicolumn{4}{|c|}{ Age at first pregnancy } \\
\hline$<18$ & $279(36.9 \%)$ & $1.62(1.19,2.21)$ & $1.82(1.23,2.69)$ \\
\hline $19-34$ & $477(63.1 \%)$ & 1 & 1 \\
\hline Yes & $554(73.3 \%)$ & $18.29(9.18,36.42)$ & $10.39(4.99,21.60)$ \\
\hline No & $202(26.7 \%)$ & 1 & 1 \\
\hline \multicolumn{4}{|l|}{ Place of delivery } \\
\hline Home & $498(65.9 \%)$ & 1 & 1 \\
\hline \multicolumn{4}{|c|}{ Maternal knowledge status on PNC service utilization } \\
\hline Good knowledge & $141(18.7 \%)$ & $9.63(6.26,14.8)$ & $7.25(4.30,12.21)$ \\
\hline Poor knowledge & $615(81.3 \%)$ & 1 & 1 \\
\hline \multicolumn{4}{|c|}{ Couples' attitude status towards PNC service utilization } \\
\hline Good attitude & $283(37.4 \%)$ & $1.77(1.30,2.40)$ & $1.76(1.16,2.69)$ \\
\hline Poor attitude & $473(62.6 \%)$ & 1 & 1 \\
\hline
\end{tabular}

\section{Discussion}

Postnatal care service utilization is one of the strategies used to reduce maternal and child mortality rate since this period is critical phase in the lives of mothers and newborn babies. The prevalence of postnatal service utilization in this study was $34.9 \%$. This finding was comparable with the study conducted in Ethiopia and India which ranges from $31.7 \%$ to $37.2 \%$ [17-19]. However, it was lower than the studies conducted in Hossana, Tanzania, and India [20-22] and higher than that of Ethiopian Demographic and Health 
Survey analysis [23]. This might be due to difference in study setting and period.

This study showed that younger mothers were more likely utilized postnatal care service than older ones $[\mathrm{AOR}=1.82$, $(95 \% \mathrm{CI}=1.23,2.69)]$.This might be due to the reason that younger mothers, especially primigravidum, did not dare to stay at their home after delivery than older mothers. This was supported by qualitative finding. A 28 years old health extension worker from Sodo zuriya district and 32 years old from Damot Sore district health office said that "...younger mother can easily adhere to health professionals' advice to utilize maternal and child health service including postnatal care. In addition eagerness to see healthy infants, fear of complications related to pregnancy and birth and absence of past experience on outcome of pregnancy let younger mothers, especially primigravida, to utilize postnatal care service than older mothers".

Study participants who followed antenatal care service in their last pregnancy were about ten times more likely utilized postnatal care service than their counter parts $[\mathrm{AOR}=10.39$, (95\% CI $=4.99,21.60)]$. This finding was in line with the study conducted in West Shewa, Hossana and Tanzania such that antenatal care visits were major predictors for postnatal care service utilization $[18,20,21]$. This might be due to the fact that antenatal care service users had opportunity to get information on timing, frequency and benefits of postnatal care service so as to visit health facility after delivery.

Those mothers who delivered their last child in health facilities were more likely utilized postnatal care service $[\mathrm{AOR}=2.66,(95 \% \mathrm{CI}=1.75,4.03)]$ than those who delivered at their home. This finding was inconsistent with the study conducted in rural Tanzania [24] such that women who delivered their child at home were more likely visited health facility for postnatal care service than those who delivered at health facility. This difference might be due to difference in the definition of postnatal care service visit. In this study women who delivered at health facility were considered as receiving postnatal care service but the previous study considered postnatal visit only if the women who made a separate visit for postnatal care service from the visit for delivery service. However, studies conducted in different parts of Ethiopia showed that institutional delivery favored postnatal care service utilization among mothers than home delivery [25-27].

Those mothers who have good knowledge of postnatal care service utilization were in favor of utilizing the service than those who have poor knowledge $[\mathrm{AOR}=7.25$, $(95 \% \mathrm{CI}$ $=4.30,12.21)]$. This finding was is in line with the study conducted in Lemo distric of Hadiya zone and Debre Markos town such that awareness on maternal complication during postnatal period was determinant factor for postnatal care service utilization [26, 27]. This finding was supplemented by qualitative study. A 24 years old health extension worker from Doge Hanchucho health post said that “...those who knew complications and danger signs during postnatal period did not miss their postnatal check up schedule". A 32 years old delivery case team leader from Gununo health center also said that "....those mothers who were aware of timing, frequency and benefits of postnatal care service during their antenatal visit utilize postnatal care service, even after home delivery, than their counterpart". Thus, equipping mothers on benefits related to postnatal care service utilization should be strengthened in the study area.

Those mothers whose couples' have good attitude towards postnatal care service utilization were 1.76 times more likely utilized the service than those mothers whose couples' have poor attitude[AOR $=1.76,(95 \% \mathrm{CI}=1.16,2.69)]$.This finding was supplemented by qualitative study. A 32 years old husband from Boloso Bombe district said that "...we husbands were responsible for utilization of postnatal care service by providing financial, moral, and emotional support to our wives". A 29 years old delivery case team leader from Bombe hospital also said that "... those mothers who visited our facility with their husbands during antenatal and delivery service were in favor of utilizing postnatal care service than those who visited alone". This guides concerned bodies working on maternal and child heath to augment couples' attitude on postnatal care service utilization.

\section{Conclusion and Recommendation}

Though postnatal care service is the key strategy to reduce maternal and neonatal mortality, its utilization by mothers was low in the study area. Younger mothers, antenatal care service utilization, institutional delivery, maternal knowledge and couples' attitude were major predictors for postnatal care service utilization in the study area. Thus concerned body working on maternal and child health service should address the above issues to promote their health.

\section{References}

[1] World health organizations. Technical Consultation on Postpartum and Postnatal Care: Department of making pregnancy safer; Switzerland; WHO; 2008. Available at: http://whqlibdoc.who.int/hq/2010/ WHOMPS10.03eng

[2] World health organizations. Recommendations on postnatal care of the mother and newborn: Switzerland; World Health Organization; October 2013.

[3] World health organizations. World Health Statistics 2014. Geneva: Available at:

http://www.who.int/gho/publications/world_health_statistics/2 $014 / \mathrm{en} /$

[4] World health organization. Make every mother and child count. Switzerland: World Health Organization; 2005. Available at: http://www.who.int/whr/2005/pdf.

[5] Ministry of Health. Health and Health Related Indicators. Policy Plan Directorate Monitoring and Evaluation Case Team. Federal Democratic Republic of Ethiopia; Addis Ababa, Ethiopia; 2008/9:12.

[6] Catalyst Consortium. Key Elements of Postpartum Care at the Community Level Based on WHO Guidelines. Available at: $\mathrm{http}: / / w w w . p a t h f i n d e r . o r g /$ publications-tools/pdfs/ 
[7] Maternal mortality estimation interagency Group (MMEIG). Trends in maternal mortality 1990 to 2010 : WHO, UNICEF, UNFPA and World Bank estimates: Switzerland; World Health Organization; 2010. Available at http://www.unfpa.org/webdav/site/global/shared/documents/p ublications /2012/pdf

[8] World Health Organization: WHO Technical Consultation on Postpartum and Postnatal Care. Geneva: WHO; 2010.

[9] Agency for Health research and quality. WHO recommendation on postnatal care of the mother and newborn. Oct2013. Available

https://www.guideline.gov/summaries/summary/47900/whorecommendations-on-postnatal-care-of-the-mother-andnewborn

[10] World Health Organization: Postpartum Care of the Mother and Newborn: A Practical Guide. Fourth edition. Geneva: WHO; 1998. WHO/RHT/MSM/983.

[11] Save the children. Postnatal Care: A Critical Opportunity to Save Mothers and Newborns. Washington, DC; population reference bureau:2007.Available http://www.prb.org/pdf07/snlpncbrie ffinal.pdf

[12] Central Statistical Agency. Ethiopia Demographic and Health Survey: Addis Ababa: Central statistical agency; 2011.

[13] WHO. World Health Statistics 2015. Available at: http://www.who.int/gho/publications/world _health_statistics/2015/en/

[14] Warren C, Daly P, Toure L, and Mongi P. 2006. Postnatal CarePractical Data Policy and Programmatic Support for Newborn Care in Africa. Cape Town, South Africa.

[15] Yinager G, Workineh, D. Factors Affecting Utilization of Postnatal Care Service in Amhara Region, Jabitena District, Ethiopia. Science Journal of Public Health. 2014; 2(3):169176.

[16] Regassa N.Antenatal and postnatal care service utilization in Southern Ethiopia: a population-based study. African Health Sciences.Sep 201; 11(3).

[17] Fikirte T, Walelegn W, Fekadu M et.al.Knowledge, Perception and Utilization of Postnatal Care of Mothers in Gondar Zuria District, Ethiopia: A Cross-Sectional Study. Matern Child Health J (2014) 18:2341-2351.
[18] Birhanu D, Nagasa D, Fikru T and Shimeles O. Institutional delivery and postnatal careservice utilizations in Abuna GindeberetDistrict, West Shewa, Oromiya Region, Central Ethiopia: BMC Pregnancy and Childbirth (2016) 16:149.

[19] Uppadhaya SK, Bhansali S, Sivodia SK, Agrawal N, Garg K, Singh M. Utilization of Postnatal Care Services in Rural Area of Western Rajasthan, India. Ntl J Community Med 2016; 7(7):569-572.

[20] Zeleke D, Nega A, Gudina E, Maternal health care use among married women in Hossaina, Ethiopia. BMC Health Services Research (2015) 15:365.

[21] Almamy MK, Christine EC, Anna ML, Factors associated with compliance with the recommended frequency of postnatal care services in three rural districts of Tanzania. BMC Pregnancy and Childbirth. (2015) 15:341

[22] Dillee PP, Baburao Nilgar, Manisha B, Determinants of postnatal maternity care service utilization in rural Belgaum of Karnataka, India: A community based cross-sectional study. International Journal of Medicine and Public Health; Jan-Mar 2014; 4 (1).

[23] Shegaw M, Leslie S, Vincentas G, Determinants of maternal health service utilization in Ethiopia: analysis of the 2011 Ethiopian Demographic and Health Survey.BMC Pregnancy and Childbirth 2014, 14:161.

[24] Diwakar M, Shivam G, Amnesty L, et al, Determinants of postnatal care use at health facilities in rural Tanzania: multilevel analysis of a household survey. BMC Pregnancy and Childbirth (2015) 15:282.

[25] Yinager Gebeyehu Workineh, Desta Aregawi Hailu. Factors affecting utilization of postnatal care service in Amhara Region, Jabitena District, Ethiopia. Science Journal of Public Health; 2014; 2(3): 169-176. doi: $10.11648 /$ j.sjph.20140203.15.

[26] Miteku A, ZerfuMulaw E, Berihun A, Postnatal Care Service Utilization and Associated Factors among Women Who Gave Birth in the Last 12 Months prior to the Study in Debre Markos Town, Northwestern Ethiopia: A Community-Based Cross-Sectional Study. International Journal of Reproductive Medicine; 2016.

[27] Tefera B, Ayanos T, Tamiru B, Postnatal Care Service Utilization and Associated Factors among Mothers in Lemo district, Ethiopia. J Women's Health Care 2016, 5:3. 